Revista Educación 25(1): 137-150, 2001

\title{
LA HUMANIZACIÓN DE LA FAMILIA: UNA RESPONSABILIDAD EDUCATIVA
}

Cecilia Villarreal $M$.

Resumen: Este artículo recoge una experiencia de investigación cualitativa sobre los significados y las percepciones sobre la "familia", así como algunas de las vivencias que experimentan en sus hogares, adolescentes estudiantes de undécimo año de colegios públicos de la provincia de Heredia.

Los supuestos teóricos de partida ofrecen una alternativa novedosa para la comprensión de las familias como un espacio interaccional de relaciones, y de gran valor educativo en la construcción humana de mujeres y hombres. Desde su propia realidad, este grupo de jóvenes, deja entrever con claridad la concepción que tienen sobre su familia, las necesidades que ésta llena en sus vidas, las dificultades de la convivencia familiar, y sobre todo, el tipo de familia que les gustaria que fuera la propia.

\section{Introducción}

La vivencia cotidiana refleja de una u otra forma la filosofía de vida de las personas, la concepción que se tiene sobre familia, las expectativas que se cifran en ella y las formas y estilos para asumir el reto de "ser y hacer familia". Esta labor social y personal se va realizando en la diversidad de condiciones y situaciones en que vivimos. En este sentido es que la familia y la convivencia familiar son finalmente una construcción social mediada por la educación y determinada por el "sentido que damos a nuestra experiencia, por nuestra situación en la estrucutura social y por nuestra práctica lingüística" (White, en Elkaim, 1988, p.10). Desde esta perspectiva no se puede generalizar y hablar de "la familia" como una entidad única, monolítica y universal; quizá deberíamos referirnos más bien a "las familias" respetando la particularidad de cada una de ellas.

No podemos obviar que cada cultura estimula formas de convivencia familiar convenientes para el desarrollo del modelo socio-económico-político que buscan los sectores dominantes. Tampoco debemos olvidar que ese modelo no siempre favorece el desarrollo de los individuos de la población en general.

El modelo de familia del sistema capitalista-patriarcal representado por el ideal de "familia nuclear", que ha prevalecido desde 
el siglo XX, ha marcado indiscutiblemente el desempeño de las familias. Este modelo parece ser el parámetro de comparación de éxito y de buen funcionamiento familiar "Occidental", indistintamente del contexto socioeconómico, del grupo étnico, el grupo etario, de la designación genérica y de la ideología religiosa. También es cierto que este modelo de familia es cada día más cuestionado por la variedad de problemas que presenta en cuanto a la dinámica y organización interna y por su interacción con otras instituciones.

Si bien es cierto, que en nuestro país la familia nuclear constituye el valor fundamental para la población (CMF, 1997), según el análisis que presenta el informe del Estado de la Nación (1998), basado en estudios recientes, la realidad costarricense muestra pluralidad y coexistencia de diferentes tipos de familia, como son las familias uniparentales a cargo mayoritariamente de mujeres y las familias unipersonales, además de las familias nucleares.

A sabiendas del dominio del ideal de familia nuclear en nuestra cultura, y de la diversidad de familias existentes, resulta interesante explorar las concepciones y significados que diferentes sectores de la sociedad le otorgan a "la familia y a la convivencia familiar". Esto es especialmente importante hoy en día debido a los diferentes tipos de familia que existen, tal y como lo plantea Coltrane (1998).

Con ese propósito es que este estudio, rescata la concepción y caracterización sobre familia, que tienen estudiantes que cursan su último año de secundaria en la provincia de Heredia.

Interesa sobremanera la población adolescente, ya que, por un lado, ésta tiene experiencia, criterio y actitud crítica para caracterizar sus experiencias familiares. Y por otro lado, su opinión nos ofrece parámetros para enriquecer la acción educativa sobre este tópico, al mismo tiempo que representa un grupo de población potencialmente activo para la creación de nuevos grupos familiares.

\section{La familia humanizante}

En familia, indiscutiblemente aprendemos a ser personas. Virginia Satir (1988) solía afirmar que "la familia es la fábrica de personas", cuando se refería a la misión de esta institución. Según esta postura, cada persona refleja inevitablemente a la familia en la cual creció y a la cual pertenece.

Entonces, el modelo educativo que se implemente en la familia, es clave por cuanto define una escala de valores para ser persona y para enfrentar la vida, así como un estilo de relaciones intra e interpersonal que necesariamente influyen en la concreción del sentido de vida que orienta el proyecto vital de cada quien.

Más que centrarse en la legitimidad del vínculo de unión, o en el ligamen por consanguinidad, o hasta si se comparte el mismo lugar de residencia; los miembros de una familia tienen una misión mayor por cumplir, cual es: ¿qué tipo de persona están formando y cómo éstas se están educando?

Con esta intención es que en este artículo hago una reflexión sobre la caracterización de las relaciones intrafamiliares acorde con la teoría del capital social y de la cercanía en los intercambios humanos. Luego, dentro de esta contextualización analizo la concepción sobre familia y algunas de las vivencias que comparte el grupo de estudiantes que participa en este estudio.

\section{La familia como instancia formadora}

Los seres humanos crecemos y nos formamos en la interacción con las otras personas con las cuales convivimos. La familia, sin lugar a duda, es el primer referente relacional, en ella se establecen necesariamente relaciones primarias, profundas y significativas, independientemente de la configuración y de la estructura del grupo familiar.

A la familia como institución social, le corresponde crear las condiciones necesarias 
para asegurar el logro equitativo del desarrollo del potencial humano y del sentido de vida tanto a las mujeres como a los hombres que la integran, para lo cual es necesario tomar en cuenta la edad, la condición genérica y las diferencias individuales.

Enfatizar en las interacciones familiares necesariamente hace pensar en el tipo de personas que queremos formar y en los valores humanos que queremos inculcar y recrear. Para formar seres responsables de sí mismos y con compromiso social es necesario reforzar el desarrollo de habilidades para mantener una adecuada autovaloración, para la reflexión crítica, la participación activa, la toma de decisiones y la disposición y apertura al cambio constante. Personas con estas características tendrán criterio y posiciones con respecto a la convivencia cotidiana, lo cual manifiesta la diversidad de formas de ver y sentir la vida. La interacción desde esta perspectiva requiere de la negociación constante y de la comunicación abierta entre las personas como condición necesaria para las relaciones respetuosas. Una tarea difícil para cada persona es poder conciliar los intereses individuales con los de la propia familia (Sprey, 1979). Lo ideal es aprender a escuchar, a discrepar, y a respetar la diferencia de opiniones, sentimientos, actitudes y actuaciones. Cuando ello se convierta en una práctica cotidiana, las relaciones interpersonales serán más fluidas, aunque no necesariamente más fáciles. Con esto quiero decir que las relaciones humanas son quizá el reto mayor que tenemos las personas durante toda la vida.

En este sentido, es que se define a la familia como una red de interacciones interpersonales. Es en este espacio social en donde las personas aprenden a relacionarse, en primer lugar consigo mismas y luego con los demás. Para Dolto (1999) la educación familiar es imborrable en la medida que ésta estructura la personalidad de cada infante y la manera de ser en la vida. Educar a un niño, dice Dolto, es tratarlo como un ser humano, y el acto educativo fluye por medio de las relaciones que se establecen entre los miembros de la familia. El propósito de la educación familiar, según esa misma autora, es inculcar el respeto del infante por sí mismo, hacerle sentir que es una persona amada y facilitarle el desarrollo de la confianza en sí mismo. Con un sentimiento de auto aceptación y de autoconfianza las personas podrán establecer mejores relaciones consigo mismas y con las otras personas.

Sin lugar a duda, la familia y la educación familiar ofrecen posibilidades para el crecimiento y el desarrollo de las personas. Esta puede ser un espacio agradable y de gran satisfacción para quienes la conforman (Satir, en Foley, 1974, Sprey, 1979; Goldenberg, I. y Goldenberg, H. 1980), siempre y cuando ése sea el propósito explícito que cimienta la construcción del grupo familiar. Desde esta perspectiva siempre estamos construyendo la familia, éste es un proceso constante, permanente y participativo de todas las personas que integran el grupo familiar.

En familia se aprende, se reproduce y reconstruye la convivencia intragenérica e intergenérica, y desde esta postura es necesario el rompimiento del paradigma patriarcal para rescatar a hombres y mujeres como seres igualmente capaces y creativos consolidados sobre principios humanos. Esta labor no es fácil pero apelamos a una educación democrática no sexista, reconocedora de la diversidad y de los derechos humanos, y sobre todo de la capacidad de hombres y mujeres para pensar, expresar, sentir y tomar decisiones para definir sus acciones, ya que "la conducta es construida a partir de la definición que la persona haga de los objetos y los eventos" (Winton, 1995, p. 137). Entonces, el actuar es un acto pensado, consciente y no robotizado. En forma individual y con la influencia de la colectividad, las personas elaboran y re-elaboran constantemente los significados que asumen como propios y que orientan sus actuaciones.

La familia debe facilitar el desarrollo de la identidad personal, entendida ésta como el descubrimiento y la construcción de quién se 
es, y de los motivos y expectativas de vida. La elaboración y re-elaboración de la identidad personal y colectiva nos lleva necesariamente a desarrollar el sentido de autopertenencia y de pertenencia social, así como la capacidad para asumirse como persona responsable, con recursos y potencialidades específicas.

Desde esta perspectiva se reafirma la actuación humana, como un proceso reflexivo y analítico mediado por la educación, que necesariamente atiende la interacción constante entre el medio social y la propia individualidad.

\section{Caracterización de las relaciones familiares}

Con miras al replanteamiento de la familia y de la convivencia interaccional y relacional familiar es necesario profundizar en la comprensión de esas relaciones. Y en este esfuerzo, el aporte de Kelly (1983) nos es de gran ayuda para caracterizar las relaciones familiares fundamentalmente por la intensidad, la frecuencia, la diversidad y la duración de ellas, sin dejar de lado la importancia e influencia del contexto sociocultural en que se encuentra la familia:

La intensidad se refiere al impacto que causa en cada quien la relación con las otras personas de la familia. Se parte del hecho de que ese impacto, aunque no sea positivo, es muy fuerte, significativo, y afecta el tipo de relaciones extrafamiliares que las personas establecen. Por la intensidad en las relaciones es que, aunque los miembros de la familia se vean en forma esporádica, se mantiene el sentimiento de pertenencia a ese grupo. Ya sea que sintamos gozo o no por nuestros familiares, hay un reconocimiento de que somos familia para bien o para mal. El sentimiento de ser parte de determinado grupo familiar permite una identificación individual y social. De allí que el apellido, el estatus y el historial familiar representan una credencial para quienes integran el grupo familiar.
La frecuencia y la diversidad en las interrelaciones en familia apuntan al tipo de actividades que se comparten y a la constancia con que ellas ocurren, independientemente del cómo se den. En familia, se comparte desde experiencias muy privadas y personales, hasta actividades superfluas. $\mathrm{Pa}$ ra compartir las vivencias familiares, se pueden desarrollar relaciones de realimentación positiva o de interferencia entre los miembros. Ello es el reflejo de los acuerdos pactados implícita o explícitamente entre los miembros de la familia.

Las familias se caracterizan también por la duración en las relaciones, independientemente de la frecuencia con que se vean, hablen, o se escriban, según sea el caso. El vínculo está presente independientemente de la distancia y del tipo de relación que se mantenga. Las relaciones cambian a lo largo del ciclo de vida de la familia y de las personas que la integran. En este sentido. la intensidad, la frecuencia, la diversidad y la duración de las relaciones van a cambiar o a tener variaciones según sean las necesidades personales y grupales, sin que desaparezca el vínculo familiar a pesar de la muerte de las personas. El finado o la finada siguen siendo parte de la familia.

En este proceso de "hacer familia", otro aporte interesante y que conjuga bien con la caracterización que se presentó anteriormente, es la teoría del "capital social". Esta nos permite comprender más de cerca el tipo de intercambios que establecen los miembros de la familia y de las ventajas o ganancias que las personas obtienen precisamente por pertenecer a ese grupo familiar.

Se entiende por capital social "las características de la organización, como son la confianza, las normas, y las redes sociales, que promueven la eficiencia de la sociedad al facilitar acciones coordinadas" (Putnam, 1994, p. 167). Se parte del principio de que los grupos donde existe confianza y cooperación entre sus miembros son más productivos y además el logro de las metas personales y del grupo se hará en forma más eficiente y 
con mayor ganancia tanto para las personas que integran el grupo como para el grupo en sí mismo.

Este tipo de organización se caracteriza por:

a- Ser una asociación voluntaria, donde se comparte con los miembros de la familia por voluntad propia. Es necesario entonces, que la familia ofrezca las condiciones necesarias para el desarrollo de todas las personas que la conforman. Así el pertencer a esa familia ofrece ganancias y fortalece el sentido de cooperación, porque vale la pena formar parte de ese grupo.

b- Desarrollar una cooperación espontánea debido a que sus integrantes conformados en grupo, contribuyen para el logro del bienestar de cada uno de los miembros. Para que una familia esté bien depende del bienestar individual de las personas que la conforman. En este sentido, cada miembro de la familia debe tener su propio proyecto de vida. Cada quien es diferente y no necesariamente se comparten los mismos intereses y valores. Esta situación inevitablemente crea algún tipo de tensiones que deben ser analizadas y asumidas en familia como un fenómeno natural y humano, apunta Sprey (1979).

La solidaridad, el interés y el cuido por todos y cada uno de los miembros de la familia es una condición que produce comodidad y bienestar a cada quien. Se pertenece a un grupo en el cual se es reconocido, considerado, y respetado (independientemente de la edad, el género y el lugar que se ocupe en el orden de nacimiento) y en donde la posibilidad de solicitar y de ofrecer ayuda cuando se requiere está siempre abierta.

c. La confianza es un componente esencial. Esta se construye a partir de la combinación de las redes de reciprocidad y de las redes de compromiso entre las personas para la búsqueda del beneficio mutuo. Para ello es necesario lograr un clima de respeto mutuo y de comunicación asertiva con reglas claras y eficaces. La comunicación asertiva se obtiene como resultado de interacciones sicológica y emocionalmente saludables. Este tipo de comunicación incrementa al mismo tiempo el nivel de autoestima de las personas, el respeto y la confianza en sí mismas. También motiva los acercamientos interpersonales y sobre todo asegura el cumplimiento de los derechos humanos en el interior de la familia (Aguilar, 1983). La práctica de la comunicación asertiva demanda del ejercicio de la autorresponsabilidad personal y familiar, ya que para poder respetar a otras personas es necesario poder hacerlo cada quien consigo mismo.

Cuando existe un compromiso compartido, las interrelaciones se dan a un nivel más horizontal, lo cual facilita la comunicación y la colaboración fortaleciendo las normas de cooperación. Las redes de relaciones horizontales permiten a los participantes y las participantes la solución de dilemas colectivos y en este sentido se logra mayor éxito institucional. Por el contrario, las redes verticales "no permiten el desarrollo de la confianza y de la cooperación independientemente de lo importante que ésta sea para las personas" (Putnam, 1994, p. 174). Cuando se buscan relaciones de subordinación es que se necesita desarrollar y mantener el tipo de relación de arriba hacia abajo y además se requiere del castigo como el arma necesaria para mantener ese orden vertical.

Según este mismo autor, en la cotidianidad, lo más común es encontrar la combinación de ambos modelos. Las redes mezclan 
ambos tipos de relaciones, las verticales y las horizontales, de tal manera que se conjugan relaciones basadas a veces en la jerarquía y otras en la igualdad.

Para crear un grupo familiar agradable para la convivencia, nos corresponde entonces aprender a hacer un uso adecuado del poder y superar las desigualdades genéricas en busca del respeto de la diversidad, y la potenciación de todos y cada uno de los miembros para así eliminar la opresión de unos sobre otros. En este proceso es necesario el entrenamiento en comunicación directa o asertiva, en el manejo de tensiones y en la solución de conflictos. Pero sobre todo, debemos ser capaces de construir un plan de vida familiar que tome en cuenta las necesidades e intereses de todas las personas que forman el grupo familiar.

\section{Método y procedimiento}

Este estudio se realiza en el marco del proyecto de Acción Social de la Escuela de Orientación y Educación Especial de la Universidad de Costa Rica "La orientación Familiar en y desde las Instituciones Educativas", desarrollado con el Núcleo de Profesionales de Orientación de la provincia de Heredia.

En esta oportunidad, el interés se centró en la recopilación de las percepciones y vivencias sobre la familia de estudiantes adolescentes de undécimo año de diez colegios públicos de la provincia de Heredia. Participaron en este estudio 78 varones y 109 mujeres en forma voluntaria, para un total de 187 jóvenes.

Las siguientes interrogantes guiaron el estudio:

¿Cómo están configuradas las familias de este grupo de jóvenes?

- ¿Cómo define lo que es "familia" este grupo de jóvenes?

¿Cómo caracteriza este grupo de jóvenes a sus propias familias?
Para dilucidar significados, vivencias y percepciones acerca de sus familias fue necesario un acercamiento investigativo cualitativo y fenomenológico, ya que su propósito es "descubrir las formas de comprensión que la gente tiene de fenómenos específicos para encuadrarlos dentro de categorías conceptuales" (Colás, 1997, p. 257). Se parte de que la comprensión de los hechos facilita las posibilidades de cambio de pensamiento y de percepción cualitativamente mejor de la realidad.

En el proceso investigativo participaron profesionales de orientación de diez colegios públicos, quienes en una primera etapa aplicaron una guía con cinco frases incompletas, que cada estudiante de un grupo de undécimo año completó de acuerdo con su experiencia de vida en su propia familia. Luego se pasó a una segunda etapa grupal de reflexión y análisis colectivo de los estudiantes y las estudiantes sobre la información que habían brindado en forma individual. En un tercer momento, para realizar el análisis general, la información recogida fue agrupada, organizada y categorizada haciendo uso de las técnicas de reducción de datos, exposición y elaboración de conclusiones.

\section{Percepciones, elaboraciones conceptuales y vivencias del grupo de participantes}

Este apartado recoge en forma sucinta y sistematizada la información que adolescentes mujeres y varones proporcionaron. Las preguntas de investigación dan la pauta para estructurar la presentación del análisis de la información recopilada.

\section{A. Configuración familiar}

Con respecto a la configuración de las familias de este grupo de jóvenes, la información recopilada arroja la siguiente tipología. 
Cuadro $\mathrm{N}^{\circ} 1$

Familias de las mujeres

\begin{tabular}{lcc}
\hline a. Madre, padre y prole & 73 & $67 \%$ \\
\hline $\begin{array}{l}\text { b. Madre y prole } \\
\text { c. Madre, padre, prole y parientes }\end{array}$ & 10 & $9 \%$ \\
\hline $\begin{array}{l}\text { d. Madre, prole, y mujeres } \\
\text { adultas parientes }\end{array}$ & 2 & $2 \%$ \\
\hline TOTAL & 109 & $100 \%$ \\
\hline
\end{tabular}

La mayoría de familias presentan las características del tipo nuclear conyugal. En segundo lugar ubicamos la familia de tipo uniparental formada por la madre y su prole. En tercer lugar se ubica la familia nuclear conyugal extendida y en minoría ubicamos la familia que aquí se denominará uniparental extendida.

Cuadro No 2

Familias de los varones

\begin{tabular}{lcc}
\hline a. Madre, padre y prole & 58 & $74 \%$ \\
\hline b. Madre, padre, prole y parientes & 9 & $11,5 \%$ \\
\hline c. Madre y prole & 5 & $6,5 \%$ \\
\hline d. Abuelo, abuela y nietos & 2 & $2,5 \%$ \\
\hline e. Padre y prole & 1 & $1,5 \%$ \\
\hline No responden & 3 & $4 \%$ \\
\hline TOTAL & 78 & $100 \%$ \\
\hline
\end{tabular}

La tipología familiar de los varones es bastante similar a la que presentan las mujeres, descrita en el cuadro $\mathrm{N}^{\circ} 1$. El tipo de familia nuclear conyugal se ubica como la primera categoría, le sigue la familia nuclear conyugal extendida. En tercer lugar y significativamente menor que la realidad de las mujeres, se ubica la familia uniparental con la madre. Después se encuentra un tipo de familia que no creo se le haya asignado un nombre aún, en donde no existe la generación de las figuras progenitoras, y una familia uniparental con el padre como la figura progenitora.

La realidad de estas familias no se aleja de la tipología familiar que presenta el Informe del Estado de la Nación (1998) y que fundamentan Kulman y Soto (1994). En su mayoría (131 de 187 adolescentes) este grupo de adolescentes conviven en familias nucleares. Y 57 jóvenes del total de 187 comparten o se agrupan en una variedad de cuatro tipos de familia diferentes. No se reportan familias unipersonales, esto se debe quizá a la tradición cultural y a la edad de la población participante en este estudio.

\section{B. Conceptualización de la "familia"}

En general, para este grupo de jóvenes, la familia es necesariamente una colectividad que aglutina a los miembros según el grado de consanguineidad y la ubicación residencial. Para definir la familia, en pimer lugar, utilizan los criterios que tradicionalmente se han enfatizado para caracterizarla, cuales son: la conformación, la ubicación y la función social de la familia como institución.

Familia "son las personas que viven en un mismo lugar" (varón). "Es el grupo base de la sociedad" (mujer). Además, se espera que el grupo familiar lo conformen las figuras progenitoras y la prole.

En segundo lugar, destacan la atención de las necesidades afectivas como una función primordial de la familia. Les parece que entre los miembros de la familia debe existir amor, comprensión, respeto, apoyo, ayuda, solidaridad y coexistencia pacífica tanto al compartir las alegrías como los problemas.

"Familia es donde todos somos amados, donde se acepta la forma de ser de cada uno, y donde cada quien expresa lo que siente y piensa" (mujer). "En la familia debe haber preocupación de todos por todos" (varón). "Se vive en paz en las buenas y en las malas" (mujer). 
En tercer lugar la familia es un espacio de aprendizaje. Para este gupo de jóvenes, a ella le corresponde educar a los hijos y a las hijas. "La familia es la base de donde aprendemos todo" (varón). "la familia es donde uno se educa, donde buscamos la solución de los problemas y se lucha por seguir adelante" (mujer).

La familia debe enseñar a sus miembros a quererse, a tolerarse, a auxiliarse unos a otros, a establecer relaciones de confianza, de comprensión y de gran unión. Y es precisamente a las figuras progenitoras a quienes estas jóvenes y estos jóvenes creen que les corresponde formarles y brindarles la atención solidaria y de respeto que andan buscando.

Finalmente, y en una condición de minoría, tanto varones como mujeres visualizan la familia como una creación divina en donde los vínculos los establece Dios.

En resumen, según las opiniones de este grupo de jóvenes, la familia humana ofrece un espacio concreto para la convivencia al mismo tiempo que cumple con las funciones educativas de primer orden en esta sociedad. Mujeres y varones destacan la función relacional y emocional que cumplen las familias, en ellas las personas deben llenar la necesidad de ser queridas, amadas y valoradas. En este sentido, el grupo familiar se convierte en el espacio interaccional más importante para este grupo de jóvenes y el espacio en donde según ellos deben sentirse bien y queridos. De no ser así, la familia será entonces un espacio de desolación y de abandono emocional que les conflictúa el desarrollo como personas.

Con estas afirmaciones, la concepción de familia que tienen en mente estas jóvenes y estos jóvenes, se acerca mucho a la familia humanizante (descrita en el apartado de sustento teórico en este artículo), la cual, sin obviar las dificultades en las relaciones humanas ofrece el espacio y la oportunidad para la construcción de relaciones saludables. Las afirmaciones de este grupo de adolescentes, refleja indudablemente la importancia, influencia e impacto que tiene la familia en sus vidas y el deseo porque ésta sea un espacio agradable, confortable, y acogedor que les dé confianza y seguridad para ser y crecer como personas.

\section{Percepciones y vivencias en el núcleo familiar}

Este apartado recoge vivencias y comentarios que varones y mujeres expresan de la propia convivencia familiar. Según las jóvenes participantes, la convivencia en familia les brinda sentido de pertenencia, y seguridad emocional. Para estas muchachas es muy importante sentirse amadas, queridas, comprendidas, apoyadas y acompañadas por los demás miembros de fa familia. "Yo sé que mi familia se preocupa por mí" (mujer), "Ellos confían bastante en mí". Estas jóvenes apelan a las posibilidades que tienen las familias para lograr una buena comunicación, "Con la posibilidad del diálogo los problemas no destruyen nuestro amor" (mujer). La familia también les ofrece ratos de esparcimiento, actividad que según ellas debiera ser más frecuente.

Los varones anotan que lo que más les gusta de sus familias es, en primer lugar la unión de la familia y en segundo lugar la seguridad que les brinda el vivir en familia. Al igual que las mujeres, los varones afirman la importancia de tener una familia afectuosa, comprensiva, cariñosa, amorosa, que les brinde apoyo, y que sea solidaria, honesta y sincera. "las familias unidas siempre por el amor es lo más importante, aunque peliemos siempre estamos juntos" (varón). Todas estas, son características que la teoría del capital social retoma como necesarias para el buen funcionamiento de un grupo cooperativo.

Los varones, a diferencia de las mujeres, destacan la importancia del apoyo económico que les brinde la familia y la relación afectuosa que tienen con sus madres. Hacen una diferencia en la calidad de la relación que tienen con el padre y la madre, la relación con ésta la presentan como más cálida y de mayor cercanía. Con el padre la relación 
es un tanto más difícil y para algunos de ellos de mayor desilución (esta idea será ampliada más adelante).

Es interesante que al referirse a los aspectos que menos les gusta de sus familias, este mismo grupo de jóvenes en forma muy clara y explícita anota los problemas y el mal manejo de los conflictos familiares. Las adolescentes se quejan de las peleas, las discusiones y los gritos, en otras palabras, la dificultad para resolver los conflictos y diferencias por medio del diálogo. "En mi familia se discute mucho y no se llega a nada, sólo que nos sentimos muy mal" (mujer). "No me gusta cuando nos peliamos con palabras" (mujer).

Los varones también acusan a sus familias de tener problemas en la comunicación, con una práctica de pleitos y discusiones constante. "La comunicación debe ser sin agresión, es con diálogo que nos podemos comunicar mejor" (varón). "En mi casa la comunicación se da más o menos porque no siempre hay diálogo, y para mí tiene que haber diálogo para que se dé una buena comunicación" (varón). Como vemos, ellos reclaman la posibidad de expresión con libertad.

Otro aspecto compartido entre mujeres y varones sobre sus propias familias y que tiene relación con el tema recién expuesto son las malas relaciones entre los miembros de la familia. Ellas sienten que se comparte muy poco entre las personas de la familia, que priva cierto individualismo, "cada quien se dedica a lo suyo sin importarle los demás" (mujer). "Existe mucho egoísmo entre nosotros en la familia" (mujer). Las figuras progenitoras no practican el diálogo entre ellas, lo cual les da inseguridad y molestias a las hijas: "Me asusta mucho cuando mis padres se pelean y se enojan entre ellos" (mujer).

Dentro de los problemas de relación, varones y mujeres destacan las relaciones con las figuras progenitoras. Afirman que éstas son relaciones muy importantes en sus vidas, las caracterizan como bastante autoritarias y limitantes para la expresión de ideas y sentimientos. En general, los muchachos y las muchachas afirman que éstas son relaciones bastante autoritarias. Las mujeres experimentan dificultad y temor para plantear lo que piensan y sienten, en especial sobre aquellas cosas que les digustan de sus familias. El ejercicio de la autoridad en la pareja es poco participativo, no pareciera que se practique la negociación entre las generaciones, destacándose los padres como más autoritarios que las madres.

Las jóvenes sienten que son irrespetadas y tienen que soportar el carácter agresivo especialmente de los padres. Los varones afirman no sentir confianza ni apoyo, y algunos de ellos expresan molestia también por el machismo del padre: "En mi casa se hace lo que papá dice y nada más" (varón). "A veces nos castigan con un jalón de pelos y orejas y ya" (varón). Pareciera que no existen mecanismos de interacción para que la prole se exprese abiertamente, por el contrario, se les controla y se les da poca participación y confianza para actuar como miembros activos de la familia.

Las jóvenes se quejan de que por el hecho se ser mujeres reciben mayor control y se desconfía más de ellas que de los varones: "tenemos menos derechos que los hombres, nos cuidan como si fuéramos niñas" (mujer). Ellas acusan también un trato de irrespeto, de sobreprotección, y hasta de incomprensión y de desatención por que no se les escucha, "Me molesta mucho el hecho que traten de manejarme" (mujer).

Se quejan también de la sobreexigencia y del recargo de labores de las tareas del hogar por el hecho de ser mujeres. "Es terrible en mi casa me exigen demasiado, tengo que estudiar, que ayudar en mi casa, que ayudar a mis hermanos" (mujer). "Me duele mucho que mis padres no sean comprensivos conmigo" (mujer). Plantean también la intromisión de unos con otros, especialmente cuando los hermanos varones las molestan y las quieren controlar también, "me enoja mucho cuando mis hermanos se meten en mis cosas, sobre todo por lo metiches que son". 
Esta situación es un ejemplo muy claro de lo que Lagarde (1995) denomina como "dialéctica patriarcal" cuando se definen y asignan en forma rígida tareas, roles y funciones especializadas según el sexo. Además del control y de las exigencias parentales, estas jóvenes enfrentan también el control y la intromisión de los hermanos varones.

Es interesante retomar la preocupación de los varones por las dificultades económicas, que aumentan cada día en sus familias. Esta situación es preocupante para ellos, les produce inseguridad el no contar con recursos económicos suficientes para atender las necesidades familiares, sobre todo por el hecho de que quisieran contar con suficiente dinero para sus gastos personales. $\mathrm{Y}$ es que el dinero es un valor de estatus, de poder y de control, es el pasaporte para moverse en el mundo público.

A manera de resumen, según la opinión y experiencia de este grupo de jóvenes, sus familias enfrentan problemas y dificultades similares a las que enfrentan otras instituciones como son: las inequidades genéricas y jerárquicas, el individualismo, y la poca cooperación entre las personas, así como también la agresión y la violencia como formas de relación, además de dificultades económicas debido al encarecimiento de la vida. Estas dificultades, en el modelo humanizante de familia, deben ser atendidas ya que no se espera que estas características sean parte del perfil de familia que se busca.

A pesar de que este grupo de jóvenes le apuesta al cambio en los estilos de relación familiar, no anotan esfuerzos concretos de su parte conducentes a lograrlo. Los cambios, según sus opiniones, deben ser realizados por las figuras progenitoras; esta actitud podría entenderse por la poca posibilidad de maniobra que sienten en sus familias, y por no sentirse corresponsables de la dinámica familiar a pesar de lo importante que es el núcleo familiar para este grupo de jóvenes.

\section{Replanteamiento de la interacción familiar}

Según la opinión de la mayoría de este grupo de adolescentes, las familias debieran realizar cambios fuertes y significativos con respecto a la dinámica familiar y específicamente con respecto a las relaciones interpersonales, intergeneracionales e intergenéricas.

Mujeres y varones consideran necesario atender los problemas y los conflictos familiares, a los que ya se han referido, las dificultades para comunicarse de una forma abierta y no tan agresiva como son los pleitos, y las discusiones constantes.

Las relaciones intergeneracionales entre las figuras progenitoras y la descendencia deben replantearse también. Las adolescentes quisieran eliminar el irrespeto y las relaciones de injusticia que establecen las figuras progenitoras, así como la sobreprotección, la indiferencia, y la sobreexigencia de sus padres. Una joven apunta "Yo quisiera que me traten como una persona independiente"; otra de ellas anota "que se den cuenta que soy una persona madura", "que me tengan confianza", apunta otra joven.

Otro aspecto interesante de destacar es el interés de algunos jóvenes varones y mujeres por establecer una relación cercana con la figura paterna. Las jóvenes acusan al padre de abuso de poder y lo responsabilizan de no atender bien la relación de pareja con la esposa ni con la prole. Ellas piden más diálogo, y confianza en la relación con su padre, "quiero poder tenerle más confianza a mi papá" (mujer) y "que hubiera confianza entre padres e hijas" (mujer), "espero que en mi familia se dé una buena comunicación para poder llevar una excelente vida" (mujer).

Las relaciones genéricas, en este caso entre padres e hijos y padres e hijas, se rigen por el sistema de relaciones culturales entre los sexos. Este no es más que una construcción simbólica establecida entre los datos biológicos de la diferencia sexual, plantea Lamas (1997). Según esta misma autora, el 
sistema relacional genérico se sostiene por la "producción de normas culturales sobre el comportamiento de los hombres y las mujeres, mediados por la compleja interacción de un amplio espectro de instituciones económicas, sociales, políticas y religiosas" (Lamas, 1997, p. 12).

Cuando la niña crece y llega a la adolescencia, en este sistema de relaciones patriarcales, agrega Wright (1991), se presenta la posibilidad de que los padres retiren o eliminen expresiones de acercamiento hacia sus hijas. Esto se da por cuanto el cuerpo de la joven está experimentando cambios biológicos profundos que los padres no pueden controlar y que además indican que la niña se convierte en mujer (en realidad mujer ha sido siempre). El problema es que el padre no pueda celebrar y reconocer el proceso de crecimiento de la hija sin sentirse amenazado, y produce en ella un sentimiento de abandono que inevitablemente le afecta en su desarrollo.

Algunos varones plantean también el deseo de cambiar el tipo de relación que tienen con su padre, les disgusta el carácter del padre, éste representa una figura autoritaria y en algunos casos además, con problemas de adicción, principalmente al alcohol. "Lo que más quisisera es cambiar la forma de ser de mi padre y la relación que tiene conmigo y mis hermanos" (varón). "En mi casa siempre se dan órdenes y hay que hacer lo que el dice" (varón). "Si yo pudiera eliminar el problema de licor de la vida de mi padre, nuestra vida en la casa cambiaría" (varón).

Algunas adolescentes quisieran que mejorara la relación de pareja entre sus padres y madres. Ellas también anotan la preocupación por problemas de adicciones por parte del padre, siendo el alcoholismo y el fumado las más comunes.

Las preocupaciones expuestas por mujeres y varones anteriormente, se refieren a las relaciones genéricas, aunque las jóvenes y los jóvenes no las denominan así. Y es que, es importante comprender que el modelo de relaciones patriarcales limita la realización de hombres y mujeres como seres humanos, debido a la ideología de dominación y opresión que sustenta a los hombres por sobre las mujeres. Esta situación se expresa en la distribución del poder, bienes, servicios, espacios, el tiempo, roles, funciones, etc. La cultura patriarcal invade las relaciones sociales, personales e institucionales.

El rol masculino se ha destacado históricamente como dominante y controlador en las familias, plantea Lerner (1986). El cumplimiento de ese rol agresivo y proveedor les limita también a los varones el rol parental, éste se caracteriza entonces por el distanciamiento del padre con la prole. Esta situación demanda mayor involucramiento de la madre con la descendencia y la atención del hogar. De esta forma la familia sacrifica el desarrollo de las mujeres como seres para sí; ellas mismas se perciben, pero también son percibidas y además exigidas, como seres para otros (Lagarde, 1992). La diferenciación y especialización de roles y funciones en el seno de la familia, inevitablemente dificulta también la relación de la pareja en cuanto los puntos de encuentro son bastante reducidos. Lo más común son los momentos de desencuentro al tratar de unir dos mundos (mujer y varón) tan distantes en la forma de concebir, y experimentar la vida.

El dinero es otro aspecto que tanto varones como mujeres mencionan entre los aspectos que deben ser atendidos en familia. Las mujeres lo enfocan como una fuente de tensión debido a las preocupaciones y problemas que causa. "Se le da mucha importancia al dinero en mi familia" (mujer). "Siempre existe una gran preocupación por salir de deudas" (mujer). Mientras tanto, para los varones la preocupación es no tener mayor acceso a la toma de decisiones y al control del dinero en la familia. Ellos quisieran mejorar la condición económica de la familia, mientras que las jóvenes lo que quieren es que no se haga problema el manejo que hacen otros del dinero en la familia.

Otro cambio que solicitan los varones es el incremento de la recreación familiar, ésta parece ser un faltante importante en la vida de estos jóvenes. 
Un dato importante de destacar es que un grupo de quince varones plantea que no considera necesario hacer ningún cambio en su familia. Podemos pensar que, ya sea que consideren que su familia está muy bien, o bien que no les disgusta la convivencia familiar con las dificultades anotadas. Otra posibilidad puede ser que no tengan opciones de cambio, ya sea por desconocer otras formas de convivencia humana o porque se han convencido de que en su familia el cambio no es posible ahora.

En resumen, las peticiones del grupo de jóvenes estudiantes, en términos generales, expresan la necesidad de vivir en familia con mayor tranquilidad y apoyo emocional. Sus peticiones apuntan hacia el desarrollo de la solidaridad, mayor confianza, y cooperación entre los miembros de la familia.

\section{Consideraciones finales}

1. En general, este grupo de jóvenes caracteriza a la "familia" como un grupo que comparte relaciones de consanguineidad y la vivienda. La familia como grupo humano cumple con las funciones de cuidar, educar y brindar apoyo afectivo a la prole. Tanto varones como mujeres consideran que entre los miembros de la familia debe existir amor, comprensión, respeto, apoyo, ayuda, solidaridad y coexistencia pacífica tanto al compartir alegrías como problemas. Eperan de sus familias: protección, seguridad, equilibrio emocional, buen trato y apoyo económico. Pareciera, por la forma en que se expresan, que el esfuerzo por tener buenas relaciones debe venir más de parte de las figuras progenitoras que de ellas y ellos mismos.

2. La vida en familia es de gran importancia para este grupo de jóvenes. Le dan gran valor a las bondades que reconocen en sus familias y expresan la necesidad del replanteamiento de sus familias en aspectos muy concretos.

En términos generales, para este grupo de jóvenes, la familia es concebida y experimentada según el tipo de relaciones que se establecen en ella. A pesar de que hicieron un esfuerzo inicial por presentar el "deber ser de la familia ideal", tuvieron luego la apertura necesaria para hablar abiertamente de la convivencia en sus propias familias. Plantearon tanto lo que les disgusta como también lo que les gusta de sus familias.

Para las jóvenes la vida en familia les brinda sentido de pertenencia y seguridad emocional, a pesar de las dificultades que también plantearon. Para los varones, vivir en familia les ofrece seguridad sobre todo cuando experimentan la unión familiar. Tanto para las muchachas como para los muchachos varones es importante tener una familia afectuosa, comprensiva cariñosa y amorosa que les brinde apoyo con honestidad y sinceridad. Plantean la necesidad de realizar cambios en las relaciones de poder y de interacción familiar. Quieren tener mejores relaciones con las figuras progenitoras, entre padre e hijos y entre padre e hijas. Destacan también la necesidad de aprender en familia a comunicarce abiertamente y a hacer un mejor manejo de los conflictos.

3. Los varones muestran mayor preocupación por la situación económica de sus familias y por el dinero que las familias les provean, ellos también plantean las dificultades de relación entre las figuras progenitoras y el desencuentro especialmente con el padre reconociendo una mejor relación con las madres.

4. Un grupo significativo de mujeres muestra descontento con el trato que 
reciben en sus familias. Expresan además, que sienten mayor control y limitaciones para ser independientes, denuncian mayor exigencia y atención de tareas en el hogar que los varones. Plantean también las relaciones de desconfianza y de dominio con el padre.

5. Aunque en general sienten seguridad y sentido de pertenencia a sus grupos familiares, este grupo de jóvenes anhela relaciones menos problemáticas, de mayor y mejor comunicación y de diálogo constante. Quisieran recibir más expresiones de afecto y de respeto en sus familias.

6. Existe coherencia entre las dificultades y los cambios que este grupo de jóvenes apuntan en sus familias. Sin embargo, estas jóvenes y estos jóvenes no parecen sentirse parte en la consecusión de esos cambios. Por el contrario muestran impotencia y poca credibilidad en las posibilidades de cambio de sus familias.

7. Este estudio nos motiva a continuar investigando aspectos como las relaciones intergenéricas, los patrones de crianza y de educación familiar. Sería importante también realizar esta investigación con madres y padres de familia y comparar los resultados.

\section{Referencias bibliográficas}

Aguilar, Eduardo. Padres positivos. México: Editorial Pax. 1983.

Centro nacional para el Desarrollo de la $\mathrm{Mu}-$ jer y la Familia (CMF), "Encuesta nacional masculinidad, salud reproductiva y paternidad responsable. Informe final preliminar". San José, Costa Rica. 1997.
Colás, M. Pilar; Buendía, Leonor; Hernández, Fuensanta Métodos de investigación en psicopedagogía. España: McGraw-Hill Interamericana. 1997.

Coltrane, Scott. "Gender and Families" USA: Pine Forge Press. 1998.

Dolto, Françoise La educación en el núcleo familiar España: Paidos. 1999.

Elkaim, Mony. La terapia familiar en transformación España: Paidos. 1998.

Foley, Vincent. An Introduction to family Therapy. New York: Grune \& Stroton Inc. 1974.

Goldenberg, I. y Goldenberg, H. Family Theory: An overview. Monterrey, California: Brooks-Cole. 1980.

Kelly Harold y otros. Close Relationships. New York: W.H. Freeman Company. 1983.

Kuhlman, Sh. y Soto, M.L. Diseño y aplicación de una tipología de hogares costarricenses 1988, 1990, 1992. Tesis de graduación Escuela de Estadísitica UCR. 1994.

Lagarde, Marcela. Identidad y Subjetividad Femenina Nicaragua: Puntos de Encuentro. 1992.

Democracia de género México: Red Latinoamericana de educación popular entre mujeres en México. 1995.

Lamas, Marta. El Género: La construcción cultural de la diferencia sexual. México: PUEG. 1996.

Lerner, Gerda The Creation of Patriarchy, Oxford: Oxford University Press. 1986. 
Proyecto Estado de la Nación. IV Iinforme del Estado de la Nación. Costa Rica: Editorama. 1998.

Putnam, Robert. Making democracy work. USA: Princeton University Press. 1994.

Satir, Virginia. The new People Making. California: Science and Behavior Books, Inc. 1988.

Satir, Virginia. Relaciones bumanas en el núcleo familiar. México: Editorial Pax. 1978.
Sprey, Jetse. "Conflict theory and the study of marriages and the family", en W. R. Burr, R. Hill, F.I.Nye, e I.L. Reiss. Contemporary theories about the family. Glencoe, Illinois: The Free Press. 1979.

Winton, Chester. Frameworks for Studing Families. Connecticut: DPG. 1995.

Wright, Nataniel. Siempre seré tu niña pequeña. E.E.U.U: Portavoz. 1991. 